\title{
TUBERCULOSIS OF LARYNX - A CASE STUDY, INDIA
}

\author{
Iqbal I, Qazi SM, Ali I, Masoodi ZA, Derwesh I \\ Department of Otorhinolaryngology, Head and Neck Surgery, Government Medical College, Srinagar, \\ Kashmir, India
}

\begin{abstract}
Tuberculosis of larynx is a rare form of tuberculosis. Patients usually present with hoarseness of voice or dysphagia and other non- specific constitutional symptoms like fever or localized pain. We are reporting a case of 55 year old male who presented to us with hoarseness of voice, odynophagia and a proliferative growth in the epiglottis which was diagnosed as laryngeal tuberculosis on histopathological examination (HPE). He also had associated pulmonary tuberculosis.
\end{abstract}

Key words: Tuberculosis, Larynx, India

\section{INTRODUCTION}

Tuberculosis of the larynx is a rare form of tuberculosis. Tuberculosis remains a serious world health problem .Each year millions of people world wide contract tuberculosis and millions die from this disease.

Tuberculosis is more common in developing countries than in developed countries. Although laryngeal involvement tuberculosis is less than $1 \%$ among tuberculosis patients, incidence of laryngeal tuberculosis has been greatly reduced due to effective chemotherapy and public health measures.

Laryngeal tuberculosis classically develops due to direct spread to the larynx from contaminated sputum but can also occur due to hematogenous spread.

More recently tuberculosis of larynx has been diagnosed by clinicians attempting to rule out carcinoma. It was seen in only one third of the cases of pulmonary tuberculosis.

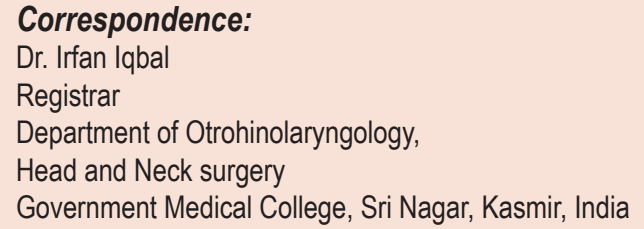

Tissue biopsy and Histopathological Examination (HPE) showing caeseating granulomas is the confirmatory diagnostic test. The patients respond well to ATT in 2-3 weeks time. This case report describes laryngeal tuberculosis co-existent with pulmonary tuberculosis.

\section{CASE REPORT}

A 55 year old male presented to us with chief complaints of hoarseness of voice, odynophagia, fever and decreased appetite of 9 months duration. He also had cough with expectoration. The patient was a chronic smoker with no history of drug abuse or alcohol consumption.

On general physical examination he was conscious, emaciated, ill looking, and a febrile. There was no clinical lymphadenopathy or scars, sinuses or clubbing.

Indirect laryngoscopy was done which revealed growth involving epiglottis and right aryepiglottic fold, vocal cords were moving with no signs of infiltration. Respiratory system examination revealed bronchial breathing, crepts on infrascapular region.

Fibro-optic laryngoscopy (fol) examination was done which confirmed our indirect laryngoscopy findings. These findings prompted us to suspect a case of carcinoma. 
Patient was evaluated and investigations revealed on chest $\mathrm{x}$-ray trachea deviated to right, fibrosis in right upper zone diffuse infiltrates on right side, non homogenous showdown right lower zone (Figure 2). Soft tissue x-ray neck showed thicken epiglottis (Figure 1), CE-CT larynx and chest revealed homogenous mass involving epiglottis and fibrosis and cavitaryn lesions in right lung (Figure 3,4).

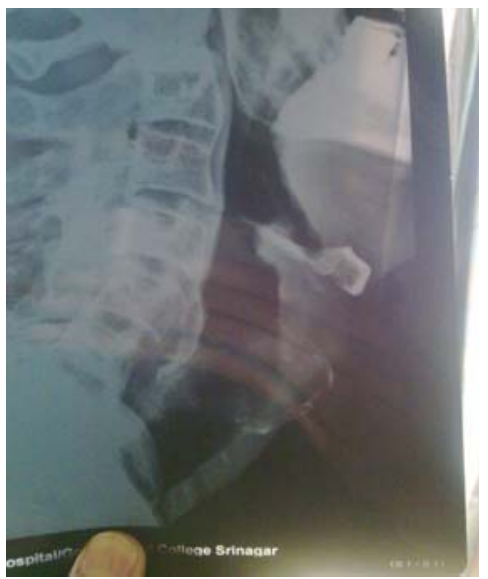

Figure 1. Soft tissue X-ray neck

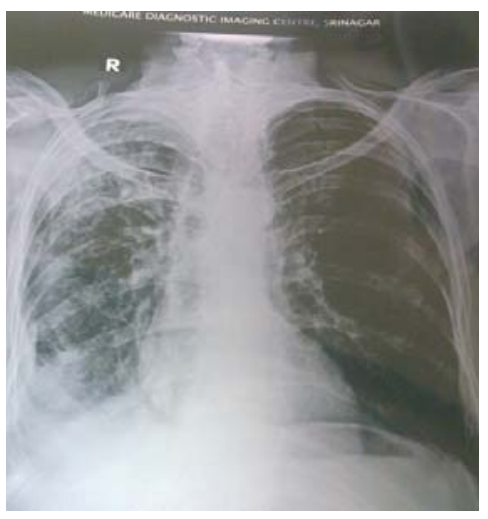

Figure 2. Chest Radiography

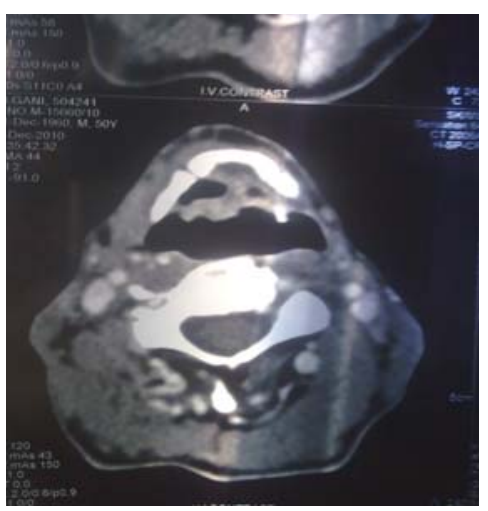

Figure 3. CT scan of larynx showing homogenous mass involving larynx

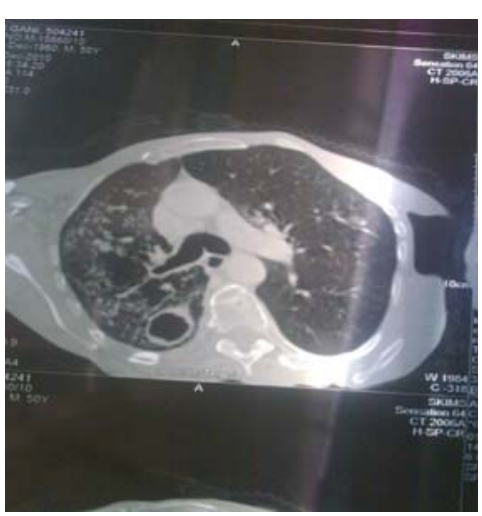

Figure 4. CT scan of chest showing fibrosis \& cavitations in right larynx

Complete blood count, bio-chemical parameters and serological tests for HIVISYPHLIS were normal. ESR was high at $55 \mathrm{~mm} / \mathrm{hr}$, AFB; were positive.

Direct examination was performed under local examination and biopsy was taken from the lesion. The pathological examination revealed caseating granulomatous lesion with lymphocytes suggestive of laryngeal tuberculosis. A standard treatment as applicable under DOTS progmame was given to patient who responded to the treatment.

\section{DISCUSSION}

Laryngeal tuberculosis is an infrequent manifestation of infection by mycobacterium tuberculosis. ${ }^{1}$ Usually, it is seen as a complication of pulmonary tuberculosis but sometimes only laryngeal involvement is possible. ${ }^{1-2}$

Laryngeal tuberculosis is the most common granulomatous disease of the larynx and has usually been considered to result from pulmonary tuberculosis although it might be localized in the larynx as a primary lesion without any pulmonary involvement. Incidence of laryngeal tuberculosis is less than $1 \%$ of all tuberculosis cases. ${ }^{2}$ Thepathogenesis of laryngeal involvement is either primary ${ }^{3}$ or secondary. Pulmonary ${ }^{4}$ lesions occur in the absence of pulmonary disease. In the present case, the laryngeal involvement was probably secondary to pulmonary disease. 
It commonly affects males more than females and the usual age of presentation is $40-50$ years ${ }^{5}$, the age of the present case was 55 yrs old which was in this range.

Early description of laryngeal tuberculosis identified the posterior part of the larynx as the most frequently affected, especially in patients who were bed ridden and in whom sputum got collected in the interarytenoid region ${ }^{6}$. The commonest part involved is vocal cords $(50-70 \%)$ and the least affected is the epiglottis. ${ }^{7}$

In the present case, epiglottis was involved which was itself a rare presentation. In our case, there was dilemma as the patient had hoarseness of voice and odynophagia only there was no h/o of hemoptysis, which made us to suspect it to be malignancy. ${ }^{5}$

Thus patients who present with hoarseness of voice with no pulmonary symptoms laryngeal tuberculosis should be considered in the differential diagnosis in any patient with unexplained hoarseness of voice.

Hemoptysis, stridor or odynophagia are other common symptoms which make it difficult to differentiate from laryngeal carcinoma.

Laryngeal tuberculosis may be categorized into (shin et al)

Polypoidal ( $22.7 \%$ )

Ulcerative ( $40.9 \%)$

Non-specific ( $27.3 \%)$

Ulcerative - fugitive mass ( $9.1 \%$ )

In our case it was ulcero-fungative type present on the epiglottis.

Direct laryngoscopy and biopsy are mandatory to establish a definite diagnosis. It should be kept in mind when differentiation between tuberculosis and malignancy is not possible. ${ }^{8}$
The basic principles that underlie the treatment of pulmonary tuberculosis also apply to extrapulmonary forms of the disease. Extra-pulmonary foci usually respond to treatment more rapidly than cavitary pulmonary tuberculosis.

\section{CONCLUSION}

This case is a warning that a growth like lesion in upper respiratory tract could be tuberculosis and efforts should be made to locate an active /inactive lesion elsewhere in the body.

\section{REFERENCES}

1. Palendira U, Spratt JM, Britton WJ, Triccas JA. Expanding the antigenic repertoire of BCG Vaccine 2005;14:1680-5

2. Oghan EF, Alper M. Epigllottic tuberculosis in a patient treated with steroids for addissions disease. Tohoku J Exp Med 2003;2:119-25.

3. Jan A. Primary laryngeal tuberculosis: a case report. J laryngol otol 1986;100:605-6(s)

4. Richter B, Fradis M, Kohler G. Epiglottic tuberculosis $\mathrm{d} / \mathrm{d}$ and treatment. Annals Otol Rhinol laryngol 2001:110:197-201(s).

5. Nishiike $S$, Irifune M. Laryngeal tuberculosis; a report of 15 cases. Ann Otol Rhinol Laryngol 2002;111:916-918(s).

6. Horowitz G, Kaslow R. Infectiousness of laryngeal tuberculosis. Am Rev Respire Dis 1976;114:241244(s).

7. Fernandes $L$, Stridor. Presentation in laryngeal in laryngeal tuberculosis. Ind J tuber 1997;44:93(s)

8. Verma SK. Llaryngeal tuberculosis clinically similar to laryngeal cancer. Lung Ind 2007;24:87-9(s). 